\title{
"Sepan quantos esta carta de procuraçion vieren...": un análisis de la comunicación política y los sectores populares en Castilla bajomedieval a partir del caso de Alfonso Sánchez del Tiemblo
}

\author{
"Sepan quantos esta carta de procuraçion vieren...": an analysis of political \\ comunication and popular sectors in late medieval Castile from the case of \\ Alfonso Sánchez del Tiemblo.
}

\section{Silvina Andrea Mondragón \\ silvinamondragon@yahoo.com.ar \\ Universidad Nacional del Centro, Argentina}

Recepción: 05 Agosto 2020

Aprobación: 19 Septiembre 2020

Publicación: 04 Enero 2021

Cita sugerida: Mondragón, S. A. (2021). "Sepan quantos esta carta de procuraçion vieren...”: un análisis de la comunicación política y los sectores populares en Castilla bajomedieval a partir del caso de Alfonso Sánchez del Tiemblo. Trabajos y Comunicaciones, (53), e142. https://doi.org/10.24215/23468971e142

\begin{abstract}
Resumen: Los modelos teóricos aportados por el antropólogo Eric Wolf y el sociólogo Charles Tilly para analizar las dinámicas del poder político, y sus múltiples formas de representación; son útiles para estudiar los circuitos de la comunicación política de los sectores populares en Castilla bajomedieval. Ambos aportan herramientas metodológicas para descifrar lógicas socio políticas y acceder al análisis tanto de lo dicho como de lo silenciado por los representantes de las comunidades de base, en el contexto de los inestables equilibrios de poder político en los grandes concejos de realengo del período.
\end{abstract}

Palabras clave: Comunicación, Política, Discursos, Castilla.

\begin{abstract}
The theoretical models contributed by the anthropologist Eric Wolf and the sociologist Charles Tilly to analyze the dynamics of political power, and its multiple forms of representation; are useful for studying the circuits of political communication of the popular sectors in late medieval Castile. Both provide methodological tools to decipher socio-political logics and to access the analysis of both what has been said and what has been silenced by the representatives of the base communities, in the context of the unstable balances of political power in the large royal councils of the period.
\end{abstract}

Keywords: Communication, Politics, Discourse, Castile.

\section{INTRODUCCIÓN}

En 1947, el historiador inglés Rodney Hilton publicó un estudio sobre la evolución económica de algunas tierras del condado de Leicester a lo largo de los siglos XIV y XV. Una de las novedades del análisis radicaba en la importancia que el autor daba a la existencia de campesinos ricos como condición para la expansión del mercado de tierras. ${ }^{1}$ Si bien desde la segunda mitad del siglo XIV el gradual desarrollo del capital productivo habría acentuado la polarización social de las comunidades de base, ${ }^{2}$ era la propia dinámica del sistema feudal la que había generado los distintos procesos acumulativos que a fines de la Edad Media consolidaron la estratificación del campesinado y por ende, la existencia de asalariados dentro de la propia comunidad 
(Hilton, R., 1947, p.95). ${ }^{3}$ En términos historiográficos esta temprana identificación de los farmers como sujetos transicionales permitió, con el tiempo, la reivindicación de la capacidad de resistencia y acción política del campesinado acomodado en torno a los cambios en las condiciones de tenencia de la tierra (Müller, M., 2005, p.313). ${ }^{4}$

De hecho, desde finales de la década de 1980 en el campo historiográfico hispano, la polarización de las comunidades y la importancia política de los rústicos atrajeron la atención de algunos historiadores que se ocupaban de analizar la dinámica histórica de los grandes concejos de realengo en la Baja Edad Media. ${ }^{5}$ Ellos ponderaron la incidencia que la autonomía de los concejos rurales tuvo sobre la morfología de la polarización socioeconómica, en tanto la propia estructura política de los grandes concejos de la meseta castellana, delegaba en los líderes aldeanos el control social y la recaudación de la renta a cambio de algunas prebendas que favorecían su enriquecimiento. ${ }^{6}$ Concluyeron que si bien el mayor o menor grado de injerencia señorial respecto de la gestión de los términos rurales en principio fue producto de las diferentes estrategias del señor, para la época bajomedieval se habían consolidado amplias jurisdicciones que alentaban la autonomía relativa de las aldeas respecto del concejo cabecera del que dependían (Santamaría Lancho, M., 1985, p.84). Sin embargo, la polarización social de las comunidades rurales no atentaba contra su reproducción. La identificación de intereses compartidos y la pertenencia estamental hacían que todavía a mediados del siglo $\mathrm{XV}$ continuaran siendo una institución dinámica. ${ }^{7}$

El conocimiento histórico actual ha planteado la «politización ordinaria de la gente común» (Oliva Herrer, H. R., 2015), reconociendo de esta manera la capacidad de los individuos para formular discursos de manera autónoma (Dumolyn, J.; Haemers, J.; Oliva Herrer, H. R. y Challet, V., 2014). Para el caso castellano específicamente, se ha sostenido que los sectores populares participaban de una esfera pública política desde sus propios recursos discursivos ${ }^{8}$. Un claro ejemplo es la revuelta de los comuneros de 1520, que presupuso desde el análisis histórico la existencia de una temprana cultura cívica (Oliva Herrer, H. R., 2018b).

De acuerdo con estas perspectivas analíticas, la cohesión, relativa o no, de estas comunidades de base dependía del articulado de un sistema de comunicación política que, por más rudimentario que fuera, debe ser abordado como un conjunto de herramientas para la acción/resistencia. ${ }^{9}$ No obstante, es claro que a los conceptos que formaban parte del sistema no se les atribuía un único significado. Es por esta polisemia que un mismo sujeto podía generar distintas adscripciones identitarias.

Pensada desde esta lógica, la identidad política no resultaba una identidad excluyente: era producto de la asunción de un conjunto de referentes compartidos que estaban a su vez mediados por determinados significados culturales que, necesariamente, debían articularse en torno a un fin político compartido.

En la actualidad, los préstamos disciplinares entre Historia y Antropología han dado por resultado novedosas formas de abordaje de la conflictividad urbana y popular bajomedieval. La cuestión de fondo es demostrar la existencia de un registro comunitario político, público y popular que contenga elementos para repensar la generación de estrategias de acción y/o resistencia de los sectores populares.

Como es lógico suponer, lo planteado conlleva un problema metodológico: ¿cómo se accede a este registro? La primera respuesta la aporta el espacio público: a través del análisis de las coplas y las canciones que se escuchaban y repetían en las calles, como así también a través del análisis de los significados fantasiosos, burlescos o graciosos que se atribuían a determinados personajes, generalmente a señores que enfrentaban al rey; porque como es de esperar, todavía a fines del siglo XV, los sectores populares eran marcadamente monárquicos (Oliva Herrer, H. R., 2011).

En este trabajo, es a través de los pleitos en los tribunales concejiles, del señor o de la propia monarquía, en los que quedaron registradas las voces de los personeros, donde buscaremos el rastro de una forma particular de comunicación política que está marcada por su propia historicidad y también por una oralidad que termina por adquirir estatuto de pleno derecho en el estudio de las múltiples violencias políticas de fines de la Edad Media. 
En este sentido, a lo largo del siglo XV, tanto la documentación municipal como la de la chancillería real evidencia una creciente cantidad de conflictos liderados por los rústicos asociados a la defensa del «bien común» (Mondragón, S., 2018, p. 12) y de la comunidad, que demuestran la actividad política del sector. ${ }^{10}$

Por otra parte, también es cierto que esta misma documentación pone de relieve un aumento de la conflictividad intracomunitaria, derivaba de la creciente cantidad de excusados que dejaban de pagar pechos, cuya cuantía era necesariamente redistribuida entre los miembros de la comunidad, y también por la marcada polarización del sector que ya en las cortes de Zamora de 1432 era reconocida por el rey como un elemento de conflictividad social:

“...en algunas çibdades e villas e lugares delos mis rregnos, los labradores por su parte fazen pueblo e vniversitat, e se ayuntan a fazer muchos rrepartimientos e derramas, los que son maiores sobre los menores, para fazer dadiuas e presentes e para otras muchas cosas que non son neçesarias, e rreparten mas delo que deuen, e los maiores enrriquecen e los menoress en pobreçen, en lo qual, les viene a los menoress grand perjuyzio e dapno, e ami deseruiçio (...) después que yo rregné acá, fueron fechos muchos caualleros e non eran nin son fijos dalgo, antes pecheros e omes de poca manera (...) de lo qual se siguen muchos pleitos e debates e escandalos e rruydos por rrazon del pechar" (Cortes de Zamora de 1432, pet. 33 y 34 )

La cita permite observar la coexistencia de dos realidades históricas en apariencia contradictorias: por un lado, el dinamismo de las comunidades de base a partir del funcionamiento de una de las instituciones que las caracterizaban (las Universidades de Tierra) y, por otro lado, su fragmentación socioeconómica, que estaría evidenciando su tendencial desaparición. Esto induce necesariamente al investigador a cuestionar si existió de hecho una comunidad política con la que los sectores populares se identificaban.

De ser afirmativa la respuesta, entonces es posible deducir la existencia de una esfera pública y por tanto unos usos políticos del espacio y del lenguaje.

\section{Alfonso Sánchez del Tiemblo: un estratega de la comunidad}

En el Asocio de la Tierra de Ávila se ha preservado una amplia gama de documentos útiles para rastrear la actuación de los representantes de las comunidades en este tipo de conflictos. De todos ellos, sobresale entre los aos 1413 y 1416 un personero extraordinario por la forma en que argumentaba sus posturas ante las autoridades y sobre todo por su conocimiento de los intersticios legales y técnicos de los pleitos, que permiten suponer que hacía un uso conveniente y estratégico de la retórica jurídica de la época.

Alfonso Sánchez del Tiemblo había sido elegido personero en cabildo abierto el 21 de octubre de 1413, junto a Juan Arias de Fuenteveros cuando los vecinos acordaron delegar en ellos la representación de la comunidad por dos años, de forma tal que "la condición de uno non sea mayor nin menor que la del otro" (Luis López, C. y Del Ser Quijano, G., 1990: doc. 68.). La primera vez que aparece el nombre de Alfonso en la documentación es el 21 de octubre de 1413 en calidad de suplente de Alfonso Jiménez que, al haberse convertido en alguacil de la cancillería, no se encontraba en condiciones de cumplir en la práctica con el cargo por su ausencia del lugar. Es probable que la razón de mayor peso para su continuidad nominal en el cargo haya sido que por ser un oficial de la monarquía, hubiera accedido a un lugar estratégico que le permitiera el acceso a información ventajosa para su comunidad. Lo señalado puede explicar el hecho de que los «hombres buenos» de la comunidad, reunidos en asamblea, hicieran caso omiso de la obligación de elegir a sus dos representantes de forma anual, derogando en consecuencia el mandato de los anteriores. ${ }^{11}$ El hecho de que esto sucediera en presencia del alcalde de la ciudad y del alguacil del condestable de Castilla (testigos y veedores de la elección como representantes del estamento señorial), aumenta las posibilidades de conferir a la comunidad de pecheros una diligencia política efectiva. ${ }^{12}$

Alfonso rápidamente se distinguió de su compañero. En un breve lapso, emergió de su pequeño concejo rural de El Tiemblo para convertirse en el representante de la ciudad y los pueblos de Ávila. ${ }^{13}$ El 8 de agosto de 1414 aparece por primera vez nombrado representante del total de los pueblos abulenses liderando un 
pleito en contra de los hijos de Pedro Gonzáles, por hornos y tierras comunales usurpadas. Más allá de la complejidad técnica del proceso, lo que interesa en este trabajo es el uso preciso del lenguaje judicial, que le permite amenazar a su contrincante sin que esto tipifique un delito, ya que se manejaba dentro de los márgenes del sistema:

“...el dicho Alfonso Sánchez dixo que pedía e rrequería al dicho Niculás Pérez, bachiller, que le conpliese la dicha carta del dicho señor rrey, en otra manera, asy non lo faziendo, dixo que protestava e protestó de se querellar dél a nuestro señor el rrey o aquien deviese con derecho e de cobrar dél e de sus bienes todas las costas e daños e menoscabos que por esta razón se rrecreçiesen a los dichos pueblos e a él en su nombre..." (Luis López, C. y Del Ser Quijano, G., 1990:doc. 72)

El reconocimiento a su actuación no se detuvo en el nombramiento como procurador de los pueblos de Ávila. Alfonso también obtuvo los favores de dos personajes poderosos: Alfonso Fernández de Orduña primero y de Velasco Fernández de Adanero después. El 28 de septiembre de 1414, el primero de ellos siendo un procurador experimentado, ya que lo era desde 1408(Luis López, C. y Del Ser Quijano, G., 1990: doc. 59), lo nombró como su procurador sustituto, llamativamente "en voz e en nombre del conçejo, caballeros et escuderos de la dicha çibdad, cuyo procurdor só,..”(Luis López, C. y Del Ser Quijano, G., 1990: doc. 80). En abril del año siguiente, Velasco Fernández, procurador de los pecheros de Ávila y de su Tierra, también nombró a Alfonso como su sustituto.

El procurador de pecheros era un cargo de importancia para el sector, sobre todo en la baja Edad Media, cuando el Regimiento excluyó en la mayoría de los grandes concejos, el voto de los representantes de los sectores populares (Rodríguez Molina, J., 2001). Tenía por objeto la defensa de los intereses del colectivo pechero ya que, por ejemplo, la apropiación de las tierras de uso comunal implicaba que las bases de reproducción material de los campesinos se redujeran. Entre el período bajomedieval y el tránsito a la modernidad, la documentación refleja que las usurpaciones de términos durante los siglos XIV y XV fueron la causa de una innumerable cantidad de procesos judiciales. Se ha demostrado que los principales implicados en las usurpaciones integraban las elites urbanas y rurales, y que, si bien algunos pares de la comunidad se apropiaron de términos, lo hicieron en nombre del afán expansionista de los principales caballeros urbanos. ${ }^{14}$

En enero de 1414, Alfonso Sánchez del Tiemblo representó por primera vez al concejo y a los oficiales de la ciudad de Ávila, en un proceso judicial iniciado contra Gil González, ${ }^{15}$ regidor del concejo de Ávila y responsable directo de la ocupación de Vacacocha, en la aldea de Riofrío. Uno de los testigos presentado por Alfonso hizo hincapié en el peso de la tradición y la costumbre: dos variantes distintivas de lo que se entendía, definía a la comunidad:

“...un echo que es de Navalasyerra e la Hoya de Rriofrío et de Peñalagraja que era común e conçegil de la dicha çibdat de Avila e du su tierra e la (sic) vido paçer por común e por conçegil, e que agora de tres años a est parte poco más o menos que Gil Gonçalez, fiio de Estevan Domingo, que lo entró e tomó e lo tiene entrado e tomado contra derecho...” (Luis López, C. y Del Ser Quijano, G., 1990: doc. 70)

Otro de sus testigos hizo referencia a lo que era de «público» conocimiento:

"Ferrán Sánchez, fijo de Sancho Ferrandes, testigo sobredicho (...) dixo este testigo que oyera decir a muchas personas e es fama pública en esta çibdat e en su tierra que Diego Gonçález del Aguila que tenía entrado e tomado gran pedaço del término conçegil que es cerca de la syerra que llaman de Peñalbueytre (...) preguntado por qué lo sabía, dixo que porque comarcava con él en el dicho término e vio que lo tenía tomado e avía oydo decir a muchas personas antiguas que eran del término de la dicha Ximensancho..." (Luis López, C. y Del Ser Quijano, G., 1990:doc. 74)

Los dos extractos citados, son ejemplos de las voces de los vecinos: en todas las pesquisas realizadas entre 1414 y 1415, los testigos de las aldeas alegaron costumbre de pastoreo y tradición como recurso de legitimación de sus derechos sobre las tierras. De manera tácita, todos los campesinos que atestiguaron recurrieron a su memoria como fundamento.

La defensa de las tierras usurpadas, tanto la de los procuradores pecheros como la de los testigos que respaldaban sus reclamos, se basaban en la tradición y la memoria, por lo que una estrategia ideal era presentar 
a comparecer al vecino más viejo de la comunidad porque era el portador de un registro valioso para el sistema judicial. $^{16}$

Tanto la memoria, como la tradición y la costumbre al tiempo que formaban parte de un ideario común de las comunidades de base, también funcionaban como dispositivos argumentales efectivos para conseguir la restitución de los términos (Monsalvo Antón, J. M., 2010). En cambio, los caballeros villanos tenían por costumbre alegar para su defensa otras fuentes de legitimidad como lo heredado por sus antepasados o bien, lo adquirido por medio de la compra. Por caso, el procurador de Sancho Sánchez, Ferrán Velázquez, sostuvo que su defendido poseía los títulos de propiedad de los artuñeros llamados de Gonzalo Gómez, obtenidos por herencia. A su vez, aseguró que los términos de Majadalosa habían sido adquiridos por compraventa (Luis López, C. y Del Ser Quijano, G., 1990: doc. 75).

En la Castilla bajomedieval, los procuradores pecheros también tenían a disposición una vía de comunicación política habilitada con el poder central. La documentación abulense contiene ejemplos al respecto que muestra que los representantes conocían la forma de acceder al poder central, sorteando el entramado institucional del concejo. Esta situación es verificable en varios procesos judiciales que tuvieron lugar en el período en cuestión, como el llevado a cabo entre enero de 1414 y abril de 1416 contra Diego González de Contreras. La comunidad había planteado la ocupación que su hijo menor de edad, Juan de Contreras, mantenía del término de Garganta de Gallegos, próxima a Riofrío. Durante el desarrollo del pleito Alfonso Sánchez del Tiemblo, en calidad de procurador del conjunto de Ávila y su Tierra, le reclamó a Nicolás Pérez, juez regio, que cumpliera lo que el rey ordenaba;

"en otra manera, asy non lo faziendo, dixo que protestava e protestó de se querellar dél a nuestro señor el rrey o a quien deviere con derecho e de cobrar dél e de sus bienes todas las costas e daños e menoscabos que por esta razón se rrecreçieren a los dichos pueblos e a él en su nombre..." (Luis López, C. y Del Ser Quijano, G., 1990: doc. 77) ${ }^{17}$

Alardeando de su llegada a rey, también encontramos Alfonso exigiendo a Sancho Sánchez que “...dexase los dichos echos et todo lo otro que tenía tomado, pues era conçejil, sy non, que lo querellarían al rrey” (Luis López, C. y Del Ser Quijano, G., 1990: doc. 75). Como hemos visto, sus principales intervenciones refieren a reclamos por la restitución de tierras comunales y pastizales usurpados, por los derechos de uso de los hornos y a la transgresión de vecinos de determinadas villas respecto de los límites de aldeas colindantes. Los fallos en favor de la comunidad que obtuvo en todos los procesos judiciales en los que actuó, evidencian la efectividad de sus estrategias discursivas y políticas.

Ahora bien, ¿qué alcance político tenía esta acumulación de poder en manos del personero, en el marco del sistema concejil bajomedieval?

El manejo del lenguaje político de Alfonso muestra que la dinámica política en los concejos de realengo era fruto de procesos de negociación entre los diferentes actores, sin los que hubiera sido imposible el equilibrio de poder que caracterizó a Castilla en el período bajomedieval. ${ }^{18}$ Pero también muestra que Alfonso manejaba una retórica política que, por básica que fuera, servía para sortear a su favor los vericuetos del sistema judicial y protagonizar los procesos al exigir, por ejemplo, la presencia de testigos y la constancia de firmas:

“...Yo, el dicho Alfonso Sánchez, en nombre de la dicha çibdad e de sus pueblos, cuyo procurador só, digo que he por rrato e por firme todo lo fecho e tratado por Pero Martínez de Manjaválago, asy çerca de la inpetraçion de la carta de la comisyón a vos deregida (...), la qual rratihabiçion pido que pongades en todos los proçesos por vos fechos. De lo qual pido testimonio signado e a los preentes rruego que sean testigos” (Luis López, C. y Del Ser Quijano, G., 1990: doc. 74: 238)

Es por este tipo de evidencias que se puede aventurar que las comunidades de base funcionaban como una entidad con capacidad de gestión política y que, por tanto, articulaba estrategias con otros actores políticos, como la monarquía. Se consolidaban así pertenencias identitarias que, al parecer, se robustecían en contextos de reforzamiento de la coacción política que se ejercía sobre ellas. Esto no significa que estemos en presencia de núcleos ideales, igualitarios y sin conflictos intrasectoriales. Aunque este tipo de cuestiones parecen restar sustento a la pervivencia de las lógicas comunitarias y vecinales en el siglo $\mathrm{XV}$, en realidad ponen de manifiesto 
la creciente importancia de la representación popular como elemento legitimador de cualquier acción y/o decisión política que involucrara a los vecinos del Común.

Las lógicas vecinales y las redes parentales y de confianza, son elementos básicos para comprender el funcionamiento de las identidades construidas por los sectores populares en la baja Edad Media castellana. El sociólogo Charles Tilly ha señalado que se puede comprobar su existencia y funcionamiento cada vez que:

1. Se compruebe documentalmente un número considerable de personas conectadas directa o indirectamente por lazos similares.

2. Se organicen reclamos importantes orientados a ayudar a otros o al grupo mismo ya que la red se refuerza en la creación de mecanismos de resistencia frente a los embates de los gobernantes.

3. Entre los integrantes cuiden, custodien o defiendan algo a largo plazo. Pero, aunque la configuración de los vínculos dentro de las redes expone a la empresa colectiva a los riesgos de malversación y fallas de los miembros individuales, se necesita primariamente que confíen unos en otros (Tilly, C., 2005) ${ }^{19}$.

En la Baja Edad Media, la importancia creciente de las plazas públicas en las villas y las parroquias en las aldeas como núcleos de sociabilidad y también la dinámica de las Universidades de Tierra, son una prueba de la existencia de estas redes de vecindad y confianza. Lo son también los sistemas de comunicación política que articularon para concretar la defensa de sus intereses. Cada uno de estos puntos los comprobamos cuando observamos la actuación política de Alfonso Sánchez del Tiemblo como representante de su sector. La cantidad de ejemplos de retórica funcional y coherente articulada por los rústicos que aporta un personaje como él, permiten observar que en buena medida, las estrategias del sector descansaban en una cierta reciprocidad que, se suponía, los gobernantes no podían eludir, al menos en lo que concernía a la «cuestión y resguardo» de la comunidad. ${ }^{20}$ En esta clave, hay que sopesar la influencia de la cultura escrita en la articulación de estrategias ya que cuando lo escrito alcanzaba el espacio público, solía hacerlo en forma de propaganda concejil o monárquica ${ }^{21}$. A partir de este entrecruzamiento, se terminaba por organizar una oralidad política, de corte público y popular. ${ }^{22}$ En esta clave, los vecinos sospechados de un primitivo sentido individualista eran los que se oponían al sentido comunitario; no era ni aceptable ni tolerable, al menos en los discursos, que reinara el interés particular por sobre el general.

Como fue señalado, el levantamiento comunero es paradigmático ya que, al involucrar al común de la población, demuestra que se necesitó de una organización, por mínima que fuera, basada en los mecanismos vecinales de transmisión de la información necesaria para llevarlo adelante (Oliva Herrer, H. R., 2018a). Bajo estos supuestos, se puede argumentar entonces la existencia de redes de información política no institucionales, pero sí vecinales.

Es claro que la ecuación privado/público en la Baja Edad Media, en realidad muestra que sólo lo que no era secreto, era público. Este es el punto en el que el espacio en tanta construcción colectiva cobra importancia para la Historia Política; en tanto generaba y atribuía significados, terminaba por favorecer la articulación de demandas y denuncias que podían llegar a formalizar cuestionamientos a la autoridad de los gobernantes.

En la medida en que se corrobora analítica y documentalmente que los procesos judiciales y los conflictos que se plantearon entre el común de vecinos y los sectores hegemónicos trascendieron las lógicas del poder local para ser planteados a la autoridad real, se puede postular la existencia de una sociedad política de base popular, legitimada por el carácter electivo de sus representantes. 


\section{Un modelo para anAlizar la comunicación política en la Baja Edad Media CASTELLANA}

Si bien el lenguaje es un fenómeno social y por tanto tiene razón de ser en sociedad, es incorporado por los individuos que, al mismo tiempo, hacen un uso sectorial o grupal del mismo ya que interactúan en desde diferentes contextos socioeconómicos y culturales. Es esto lo que da el carácter discordante a la comunicación humana, y al lenguaje un potencial de cambio social, porque contiene herramientas discursivas para para organizar la resistencia o la lucha social.

En este sentido, la articulación de cualquier mecanismo de cooperación intra o extra sectorial, así como cualquier atisbo de cooperación, implican equilibrios de poder para los que son esenciales las palabras ya que, al ser por todos conocidas, se convierten en instrumentos eficaces para el funcionamiento de estas interdependencias, siempre cambiantes.

Analizando el tema de poder en las relaciones humanas, y sus múltiples representaciones, el antropólogo estadounidense Eric Wolf ha ofrecido un modelo general de funcionamiento, según el cual se despliegan cuatro tipos de poder en los grupos humanos. ${ }^{23}$ Entre los diferentes tipos que ofrece, interesa enfocar en el poder táctico o de organización porque es el tipo teórico que permite explicar la dinámica del poder político de los grandes concejos de la Extremadura histórica castellana en la Baja Edad Media. De acuerdo con su esquema, el poder táctico se desarrolla cuando "el poder controla los contextos en los que las personas exhiben sus propias capacidades e interactúan con los demás. Este sentido centra la atención en los medios por los cuales los individuos o los grupos, dirigen o circunscriben las acciones de los demás en determinados escenarios" (Wolf, E., 2001, p.20).

De acuerdo con este esquema, los sistemas de ideas cobran entidad sólo a través de la comunicación y la organización de discursos. Por lo tanto, es fundamental prestar atención a la forma que estas ideas trascienden el ámbito de lo privado para alcanzar lo público y convertirse en herramientas para la acción; y, sobre todo, conocer de quién a quién y entre quiénes se comparten. No obstante, no se debe circunscribir el acto comunicativo a las palabras; la documentación castellana bajomedieval muestra que también los mensajes o las ideas que se transmiten por medios no verbales también forman parte de los sistemas de comunicación política. Es por esto que poder aislar la forma en que se representaba lo que se quería comunicar, en esencial para formular cualquier intento de explicación.

Todos los constructos sociales, incluidas las cosmogonías colectivas y el lenguaje, son producto, en última instancia, de relaciones de poder observables a través de determinados símbolos culturales, que nunca son estáticos e inflexibles (Guinzburg, C., 1976).

Bajo esta premisa analítica, todavía resta ponderar y delimitar el significado de las diferentes manifestaciones de la acción política popular a fines de la Edad Media. Palabras como ruidos, alborotos, escándalos y rumores aparecen reiteradamente en la documentación. En tanto podía ser el mismo rey el que justificaba una medida en la necesidad de garantizar el bien común, silenciar los ruidos o amilanar los escándalos, estas palabras se convertían axiomáticamente en lenguaje político.

Un ejemplo de esto lo encontramos en el mes de abril de 1487, cuando los reyes Fernando e Isabel emplazaron a las autoridades del concejo de Ávila con el fin de garantizar la buena administración del concejo, de acuerdo con lo dictaminado en las cortes de Toledo celebradas en 1480. En la carta enviada hicieron hincapié en el interés que tenían en garantizar el bien público de la villa, en atacar cualquier atisbo de corrupción vinculado a las derramas, la imparcialidad de los oficiales de la justicia o los desmanes de los fieles en los pesos y medidas; y en mantener en funcionamiento y en buen estado los bienes públicos del concejo (en este caso particular los puentes). Sin embargo, llama la atención el énfasis que pusieron en el resguardo tanto del espacio como del carácter público de algunos delitos al ordenar:

"punir e castigar los delitos e pecados públicos contra los renegadores e blafemadores e jugadores e los que tienen tablero públicos e contra las mançebas de eclesiásticos e casados en tal manera que sean castigados que non ayan nin puedan aver 
lugar de quedar en su pecado e contra lo sotilejios e adivinadores e os otros pecados públicos...” (Casado Quintanilla, B., 1994: doc. 60)

La cita documental permite inferir que tanto el rumor como el chisme podían tornar inestable el equilibrio de poder en las villas bajomedievales. Lo escrito por los reyes permite observar que cualquier acción de resistencia o protesta popular se expresaba a través de unos códigos comunicativos particulares, al que hay que poder acceder para decodificar sus símbolos y significados políticos. En castilla bajomedieval, el lenguaje de la resistencia popular confirma que la violencia siempre es significativa, significante y ritual. Esto lo podemos ratificar cuando en las denuncias se repiten a menudo determinados tipos de acusaciones que denigran ética o moralmente a los representantes del sector, a los oficiales del concejo o a los regidores. Lo hacían porque se suponía que en tanto «representantes», debían mantener una reputación que fuera intachable, capaz de resistir los cuestionamientos de la voz popular. ${ }^{24}$

De todo lo que se solía endilgar ritualmente a alguien, hay que poder aislar específicamente lo que ofendía el sentido comunitario. Los documentos muestran que muchas veces, la actuación violenta en realidad esconde la defensa de lo que se entiende como lo «justo». Es probable que todos los resortes de la justicia popular aparezcan cuando se diluyen los mecanismos coactivos de la justicia formal. Es entonces cuando la muchedumbre se siente legitimada por la ineficacia, o la parcialidad, de los dispositivos judiciales institucionales.

La comunicación es en esencia un acto social que presupone una composición jerárquica de los discursos. Es por esto por lo que en la gran cantidad de cartas que los procuradores pecheros como Alfonso Sánchez, enviaron al monarca, era prudente evitar algunos relatos en favor de otros que sí eran convenientes, lo que hace lo que no dicho o expresado se transforme en un dato de la realidad. ${ }^{25}$

También el análisis histórico puede beneficiarse de una concepción social del espacio: escenario en el que se intercambias ideas y se tejen redes comunitarias que forjan ciertos criterios de lo que está bien y de lo que está mal; lo que es aceptable o de lo que no está permitido. Se moldean así identidades sectoriales que se asocian también a una cultura política y jurídica que se refuerza así misma a partir de su propia dinámica histórica (Hespanha, A., 1989, p.99).

Para la Historia Política, el espacio en tanto construcción social es fundamental. En el caso castellano, solo por citar un ejemplo, el derecho a la representación era conexo a la condición de vecino, que era a su vez una condición jurídica. La ecuación que se daba entre el acceso a los derechos vecinales y comunitarios y el marco territorial explica en gran medida el mapa político del reino de Castilla a fines de la Edad Media. ${ }^{26}$ En la Castilla del siglo XV, el espacio público y popular comenzó a identificarse con las calles de las villas, los atrios de las iglesias y las ferias. Pero también lo hizo con una cantidad de palabras, gestos y símbolos que exponían la existencia de una esfera propia de lo público y popular. ${ }^{27}$

\section{Conclusiones}

Como es sabido, los dispositivos políticos institucionales y los cargos disponibles en los grandes concejos de realengo de la meseta castellana, fueron atravesados por un proceso de señorializaron y patrimonialización que acompañó la imposición del Regimiento desde la segunda mitad del siglo XIV. No obstante, la gente común aparece en la documentación municipal a lo largo del siglo XV, sosteniendo pleitos contra caballeros, organizando resistencias o sellando acuerdos con los poderosos. Se constata así una mayor participación política de las comunidades de base, aunque no restringida únicamente a los canales políticos formalmente reconocidos. Es por esto por lo que se vuelve necesaria una definición más inclusiva de lo que se entiende por «lo político» en sociedades concejiles bajomedievales. Tal vez sea necesario considerar la funcional imbricación entre lo político, lo ideológico y lo cultural para acceder a una definición ampliada de lo que entendemos por dinámica del poder político. Desde esta perspectiva, cobran importancia las múltiples identidades e identificaciones populares generadas en el período para cuyo estudio 
es esencial el análisis del lenguaje y los códigos para la comunicación política que se construyeron.

Como hemos visto, los modelos teóricos como el del poder táctico o de organización, ideado por el antropólogo Eric Wolf, o el de las redes de confianza propuesto por el sociólogo Charles Tilly, resultan útiles para analizar lógicas socio políticas bajomedievales ya que proveen herramientas metodológicas para acceder al análisis de lo dicho y lo silenciado por los vecinos del común, en el marco de la acción y de la resistencia política del período. Cada vez que el historiador puede descubrir el funcionamiento o la existencia de una red de confianza y vecindad, puede acceder a lo que a nivel identitario anidaba en la costumbre y aportaba lo que de esencial y específico tenían los sectores populares de la época, sobre todo a nivel de sus dinámicas políticas.

Es por esto que el estudio de las palabras, los rumores, los chismeríos, en fin, lo que era «por todos conosçido», se transforma en materia de investigación. Cuestiones como la capacidad de articular elementos retóricos de utilidad para la acción y la resistencia comunitaria, ponen en tensión la autonomía política de los discursos tanto del común de vecinos como los de los sectores hegemónicos.

\section{REFERENCIAS}

Asenjo González, M. (1984). "Labradores ricos: nacimiento de una oligarquía rural en la Segovia del siglo XV", En la España Medieval, 4 .

Carrasco Manchado, A. I. (2003). Discurso politico y propaganda en la Corte de los Reyes Católicos (1474-1482), Universidad Complutense de Madrid.

Casado Quintanilla, B. (1994). Documentación Real del Archivo del Concejo Abulense. (1475-1499), España, Institución Gran Duque de Alba.

Cea, M. y Bonachía, J. (1998). "Oligarquías y poderes concejiles en la Castilla bajomedieval: balance y perspectivas", Revista d'historia medieval, 9.

Cortes de los Antiguos Reinos de León y Castilla. (1866). Real Academia de la Historia, III, Madrid.

Da Graca, L. (2009). Poder politico y dinámica feudal. Procesos de diferenciación social en distintas formasseñoriales (siglos $X I V-X V I)$. Valladolid: Universidad de Valladolid.

Del Ser Quijano, G. (1998). Documentación Medieval en archivos municipales abulenses, Diputación de Ávila

Del Val Valdivieso, M. I. (1994). “Ascenso social y lucha por el poder en las ciudades castellanas del siglo xv”, En la España Medieval, 17, 157-184. Recuperado de: https://revistas.ucm.es/index.php/ELEM/article/view/ELEM $9494110157 \mathrm{~A} / 23448$

Dumolyn, J. (2012): "Political communication and political power in the Middle Ages: a conceptual journey", Edad Media. Revista de Historia, 13, 33-55. Recuperado de: https://dialnet.unirioja.es/servlet/articulo?codigo=396 3346

Dumolyn, J., Haemers, J., Oliva Herrer, H. R. y Challet, V. (2014). The voices of the people in late medieval Europe: communication and popular politics. Studies in European History 33. Bélgica: Brepols.

García de Valdeavellano, L. (1968). Curso de historia de las instituciones españolas. De los orígenes al final de la Edad Media. Madrid: BCHRO.

Guinzburg, C. (1976). El queso y los gusanos. El cosmos según un molinero del siglo XVI. Italia: Einaudi.

Hespanha, A. (1989). Visperas del Leviatán. Instituciones y poder político. Portugal, siglo XVII. Madrid: Taurus Humanidades.

Hilton, R. (1947). The economic development of some Leicestershire estates in the XIV and XV centuries. Londres: Oxford University Press.

Luis López, C. y Del Ser Quijano, G. (eds.) (1990). Documentación medieval del Asocio de la extinguida Universidad y Tierra de Ávila, Tomo I, Diputación de Ávila.

Nieto Soria, J. M., (1993). Ceremonias de la realeza, propaganda y legitimación en la Castilla Trastámara, Madrid, Nerea. 
Nieto Soria, J. M. (1995). "Propaganda política y poder real en la Castilla Trastámara: una perspectiva de análisis", Anuario de Estudios Medievales, $\mathrm{N}^{\circ} 25$, vol. 2.

Nieto Soria, J. M., (2007). Propaganda y opinión pública en la Historia. Universidad de Valladolid.

Nieto Soria, J. M., (2009). “Ceremonia y pompa para una monarquía: los Trastámara de Castilla”, Cuadernos del CEMYR, $\mathrm{N}^{\circ} 17$.

Mondragón, S. (2018). "Los usos políticos del espacio público en algunas villas del norte de Castilla, siglos XV y XVI", Trabajos y Comunicaciones, 2da. Época, 48. Recuperado de: https://www.trabajosycomunicaciones.fahce.unlp. edu.ar/article/view/TyCe069

Monsalvo Antón, J. M. (1988). El sistema político concejil. El ejemplo del señorío medieval de Alba de Tormes y su concejo de villa y Tierra. Salamanca: Ediciones de la Universidad de Salamanca.

Monsalvo Anton, J. M. (1989). "La participación política de los pecheros en los municipios castellanos de la baja Edad Media. Aspectos organizativos”, Studia historica. Historia Medieval, 7, 37-93. Recuperado de: https://revistas.u sal.es/index.php/Studia_H_Historia_Medieval/article/view/4369

Monsalvo Antón, J. M. (1990). "La sociedad política en los concejos castellanos de la meseta durante la época del Regimiento medieval. La distribución social del poder". En Concejos y ciudades en la Edad Media Hispana, II Congreso de Estudios Medievales. Madrid.

Monsalvo Antón, J. M. (2010). "Costumbre y comunales en la Tierra medieval de Ávila (observaciones sobre los ámbitos del pastoreo y los argumentos rurales en los conflictos de términos)», Comunalismo concejil abulense. Paisajes agrarios, conflictos y percepciones del espacio rural en la Tierra de Ávila y otros concejos medievales. Ávila: Institución Gran Duque de Alba.

Monsalvo Antón, J. M. (2017). "El conflicto «nobleza frente a monarquía», en el contexto de las transformaciones del estado en la Castilla trastámara. Reflexiones críticas”. En J. A Jara Fuente (coord.) Discurso político y relaciones de poder. Ciudad, nobleza y monarquia en la baja Edad Media. Madrid: Dykinson.

Müller, M. (2005). "Seignioral control and the peasant landmarket in the 14th century”. En L. Feller y C. Wickham, Le marché de la terre au Moyen Age. Roma: Ecole Française de Rome.

Oliva Herrer, H. R. (2011). “ «La prisión del rey»: voces subalternas e indicios de la existencia de una identidad política en la castilla del siglo XV", Hispania. Revista Española de Historia, vol. LXXI, $\mathrm{N}^{\circ} 238$.

Oliva Herrer, H. R. (2014). "¿Qué es la comunidad? Reflexiones acerca de un concepto político y sus implicaciones en Castilla a fines de la Edad Media”, en Medievalismo, 24, 281-306. Recuperado de: https://revistas.um.es/m edievalismo/article/view/210601/167811

Oliva Herrer, H. R. (2015). “Sobre la politización ordinaria de la gente común a fines de la Edad Media”, Una nueva visión de la Edad Media: legado y renovación, XXVI Semana de Estudios Medievales. Nájera: Instituto de estudios riojanos.

Oliva Herrer, H. R. (2018a). "Sermones políticos y audiencia: una visión crítica de la predicación en vísperas de la guerra de las comunidades en Castilla", Revista de história da sociedade e da cultura, 18, 49-68. Recuperado de: https://digitalis.uc.pt/en/node/122918

Oliva Herrer, H. R. (2018b). "Juntar al pueblo: sobre las dimensiones espaciales de la movilización popular en las ciudades castellanas a fines de la Edad Media”, Trabajos y Comunicaciones, $2^{\circ}$ época, $\mathrm{n}^{\circ}$ 48. Recuperado de: htt ps://www.trabajosycomunicaciones.fahce.unlp.edu.ar/article/view/TyCe068

Pastor de Togneri, R. (1984). "Sobre la articulación de las formaciones económicosociales: comunidades de aldea y señoríos en el norte de la Península Ibérica (siglos XXIII)". En AA.VV., Estructuras feudales y feudalismo en el mundo mediterraneo (siglos X-XIII). Barcelona: Crítica.

Rodríguez Molina, J. (2001). “El personero, defensor de la comunidad ciudadana”, Gazeta de Antropología, º 17.

Santamaría Lancho, M. (1985). "Del concejo y su término a la comunidad de ciudad y tierra: surgimiento y transformación del señorio urbano en Segovia (XIII-XVI)", Studia Histórica. Historia Medieval, 3, 83-116. Recuperado de: https://revistas.usal.es/index.php/Studia_H_Historia_Medieval/article/view/4325 
Sevillano Calero, F. (2005). "La formación del "espacio público" como factor de cambio político: precisiones al concepto de "publicidad burguesa", Memoria y civilización, 8, 185-203. Recuperado de: https://dialnet.unirio ja.es/servlet/articulo?codigo $=2271781$

Solórzano Telechea, J., Arízaga Bolumburu, B. y Haemers, J. (coords.) (2014). Los grupos populares en la ciudad medieval europea. La Rioja: Instituto de Estudios Riojanos.

Tilly, C. (2005). Trust and Rule. Londres: Cambridge University Press.

Wickham, C. (1998). "Gossip and resistance among the medieval peasantry", Past and Present, 60.

Wolf, E. (2001). Figurar el poder: ideologias de dominación y crisis. México: Ciesas.

\section{Notas}

1 Para el caso castellano, la venta de tierras por parte de los campesinos acomodados es clara a mediados del siglo: "a cinco días del mes de junio, año de mil e quatroçientos e setenta e ocho años, vendió Juan Gonçález al conçejo un pedaço de tierra que es de su mujer, Mari Alonso, fija de Juan Gutierrez, que Dios aya, la qual tierra le cayó de su abuela, Mari Gonçález e la vendió al conçejo con liçençia e abtoritat de la dicha María Alonso, su mujer..." (Del Ser Quijano, G., 1998: doc. 128, Navarredonda de Gredos).

2 Las comunidades de base eran el ordenamiento social básico del espacio rural, en el que se agrupaban los campesinos a despecho de la diferenciación social del sector: "de hecho, la comunidad se identifica con «la célula básica» de la clase campesina en la época medieval, es decir el campesinado adquiere la condición de sujeto colectivo a través de su organización en comunidades", (Sánchez León, P., 2007, p. 332). Es evidente que acuerdo con la identificación de las comunidades de base con una forma específica de ordenamiento social del territorio. Sin embargo esta forma de entenderlas es producto de un recorrido historiográfico que se inició a principios de los años ' 80 del siglo XX, cuando Reyna Pastor se abocó al estudio de las comunidades campesinas al trasluz de la forma germánica propuesta por Marx (Pastor, R., 1984, p. 106). Para ella, las comunidades de aldea no eran instituciones transicionales sino que constituían una forma particular de habitar el espacio que tenían por fin concretar la explotación de los recursos naturales y aprovechar los comunales.

3 "It was to be expected that the disintegration of tenements, and the re grouping of lands, should lead to a sort of polarization process in which on the one hand richer peasants would build up farms above the size of the normal virgate holding of 20 to 30 acres, and on the other hand the poor would lose what land hey had and tend to become labourers" (Hilton, R., 1947, p. 100).

4 Desde el marxismo británico, los trabajos de Miriam Müller (entre otros) demostraron la capacidad de resistencia de los «farmers» no sólo por la fuerza sino a través de estrategias legales y de pasividad cotidiana frente, por ejemplo, a los recaudadores de renta. Con una alfabetización básica, transitaron en el siglo XIII, pero también en el XIV y en el XV, tribunales locales y reales procurando la defensa de la comunidad en contra de los embates del estamento superior.

5 Entre finales de los años ' 80 y principios de los ' 90 del siglo XX, José María Monsalvo Antón, Isabel del Val Valdivieso y María Asenjo González avanzaron en el estudio de los sectores enriquecidos del campesinado, demostrando su capacidad de resistencia por un lado y la forma en que la elite del común incidía en las decisiones del gobierno municipal bajomedieval. Al respecto ver: J. M. Monsalvo Antón (1988; 1989; 1990); M. Asenjo González (1984); M. I. Del Val Valdivieso (1994) y M. Cea y J. Bonachía (1998).

6 Una de las peticiones hecha en las Cortes de Madrigal, permite conocer algunas características propias de la acumulación patrimonial de una fracción del campesinado. Se observa que disponen en usufructo parcelas de tierras dispersas fuera de su comunidad, y que en los lugares de señorío, se enfrentan por la mano de obra a los señores del lugar: "sepa vuestra merçed que muchas delas personas que biuen e moran en algunas delas vuestras çibdades e villas de vuestros rregnos e sennorios que son dela vuestra corona rreal tienen muchos heredamientos en algunas villas e lugares de sennorios, asi heredades de tierra de pan leuar e vinnas commo casas e prados e fueros e otros derechos e cosas queles pertenescen, los quales han rresçibido e rresçiben caa dia muchos agrauios e dapnos e syn rrazones delos sennores a do asi tienen los dichos sus heredamientos, poniendo les e demandando les inpusiçiones neuas e defendiendo a sus vasallos que les non arrienden nin labren nin administren las dichas sus heredades, e así mesmo faziendo les mouer muchos pleitos e contiendas a fyn delos fazer perder los dichos sus heredamientos" (Cortes de Madrigal de 1438, pet. 53)

7 Estudios comparativos han demostrado que, en Castilla bajomedieval, el grado de la polarización social de las distintas comunidades, dependía de las formas de gestión del señorío en períodos de reproducción plena (Da Graca, L., 2009).

8 En este trabajo aparecen identificados los términos sectores populares con común de pecheros, o comunidades de base en tanto «pueblo». De la misma manera, los términos se distinguen del Común urbano, que para la época tenía una clara una connotación política-jurídica (Solórzano Telechea, J., Arízaga Bolumburu y Haemers, 2014). 
9 Para un análisis de las diversas connotaciones que el término «comunidad» adquirió a lo largo del siglo XV, ver: $\mathrm{H}$. R., Oliva Herrer (2014).

10 En 1425, en las Cortes de Palencia, los procuradores del Común denunciaron con firmeza los abusos de los sectores señoriales, con lo que se demostraría el gradual incremento de la agencia política de los sectores populares, o al menos de sus representantes.

11 No es el único caso de «desobediencia» en la elección de los representantes pecheros, encontramos varios casos similares, por ejemplo, en la asamblea de 1409 mantienen en el cargo a Pero Ximénez de Truxillo (Luis López, C. y Del Ser Quijano, G., 1990: doc. 61).

12 “... cónmo nos, los omes buenos pecheros de tierra de la çibdad de Avila e de sus pueblos, estando ayuntados a nuestro cabilldo general, por poner nuestros procuradores e nuestros fazedores, en la iglesia de Sanct Gil de la dicha çibdad, et estando ay Bartolomé Rrodriguez, bachiller en leyes, alcalde en la dicha çibdad e Juan de Mendoça, alguazil otrosí en la dicha çibdad por el Condestable de Castilla..." (Luis López, C. y Del Ser Quijano, G., 1990: doc. 68)

13 Es sabido que Ávila era uno de los más grandes concejos de realengo, con un amplio alfoz rural y con una sólida trayectoria institucional, de gran importancia y peso en el juego político de la corona castellano bajomedieval. Esta característica distintiva es la que confiere a la trayectoria política de Alfonso Sánchez, ribetes extraordinarios.

14 J. M. Monsalvo Antón (2001) provee una descripción detallada del patriciado urbano, mayormente eran los que organizaban las usurpaciones de términos de Ávila en los siglos XIV y XV. En consecuencia, pusieron en práctica lógicas familiares, donde los hijos heredaban bienes ocupados por sus antepasados de la misma manera que heredaban los bienes adquiridos de forma lícita.

15 Gil González y Alfonso Sánchez aparecen como dos figuras arquetípicas y emblemáticas del clásico enfrentamiento a escala local entre caballeros y pecheros por la usurpación y defensa de comunales en el feudalismo tardío castellano. Gil González era hijo de Esteban Domingo y pertenecía al linaje de los Dávila-Casa de Cespedosa, familia titular del señorío de Cespedosa y Puente del Congosto. A juzgar por la evidencia documental, es probable que Gil y Alfonso, tuvieran un conocimiento personal del accionar del otro ya que "Gil González Dávila se había hecho con importantes propiedades en términos de El Tiemblo”. (Monsalvo Antón, 2001, pp. 97-112).

16 Se encuentran ejemplos como el que sigue: "estos exidos, que asy tiene tomados el dicho Diego Gonçález, que sean comunes de la dicha çiudat e su tierra, dizo que sabía que sy por cuanto los él paçiera con sus ganados e los viera paçer muchas vezes a los vecinos de la dicha çiudat e de su tierra syn ge lo contradecir persona alguna..." (Luis López, C. y Del Ser Quijano, G., 1990: doc. 74).

17 En este pleito, a su vez, podemos ver cómo Alfonso Sánchez del Tiemblo acusa de «rebeldía» a Diego González, por no responder a los escritos y a las audiencias acordadas, para dar por finalizado el proceso judicial. Este recurso discursivo es utilizado reiteradas veces por el procurador pechero, con el objetivo de que el juez dictara sentencia a su favor, restituyendo los términos usurpados por el hijo de González.

18 Sobre el equilibrio de poder en el área de los grandes concejos de realengo, ver J. M. Monsalvo Antón (2017)

19 C. Tilly también aporta las características que distinguen a los "rulers" (los gobernantes) en relación al funcionamiento de las redes de confianza: "Rulers are national authorities and actors; governmental agents are those who act or speak on behalf of rulers; governments are the organizations those agents operate; political actors are non-governmental entities having some sort of name and standing vis a vis a given government and regime for regular relations among rulers, governments and political actors; public politics refers to their visible interactions" (Tilly, C., 2005, p.4).

20 Un ejemplo de lo expresado lo encontramos en 1495, cuando los reyes Fernando e Isabel comisionaron a su corregidor en Ávila, para que actuara en una denuncia que los vecinos del concejo rural de Riofrío habían hecho en contra del regidor abulense Francisco de Abril. Los vecinos habían mandado carta a los reyes pidiendo que intervengan a su favor, dando por sentado que lo harían, porque encontraban grave la situación porque se estaba afectando un resorte básico de la comunida: la imparialidad de la justicia: denunciaron que el regidor "los haze atr presos porque la justicia faze lo que él quiere (...) hacen otros muchos vituperios a los vecinos del dicho lugar: a unos dar de palos e abofetear la mugeres casadas, e a otros muy muchas syn razone e agrauios tan feos", Casado Quintanilla, B. (1994: doc. 107).

21 Sobre el sentido y la función social de la propaganda en el mundo medieval, ver: (Dumolyn, J., 2012). Para el caso castellano en la Baja Edad Media existe una notable producción científica que en los últimos años ha dado por resultado trabajos de calidad; al respecto: J. M. Nieto Soria (1993; 1995; 2007; 2009) y A. I. Carrasco Manchado (2003).

22 En un artículo que apareció en la revista Past and Present, Chris Wickham (1998) demostraba la importancia del chusmerío y del rumor como contingentes de lo político en sociedades medievales. El autor demostraba que un rumor se podía transformar en información política cuando adquiría status público.

23 Eric Wolf distingue en su modelo cuatro variables: el poder del individuo, el que hace que un ego se imponga a un alter, el poder táctico y por último, el poder estructural. La descripción del esquema completo en Wolf, E. (2001).

24 Por ejemplo, es habitual encontrar en la documentación concejil que se acuse a los arrendadores de rentas de malversación de fondos, aparecen bajo este tipo de formulaciones: "sepades que a nos es fecha relación que Juan Gonçález e Pajares, procurador e escriuano de los pueblos de esa dicha çibdad, ha tenido cargo de los repartimientos e gastos que en los dichos 
pueblos se han fecho e gastado en os años de nouenta e uno e nouenta e dos años, el qual diz que non ha dado cuenta de los maravedis que se han cobrado e repartido e gastado en los dichos pueblos ..." Casado Quintanilla, B.(1994: doc. 92).

25 Tanto las denuncias planteadas en los ámbitos del poder central por parte de los procuradores pecheros, como las cartas que los reyes envían a sus corregidores o a los mismos procuradores, siguen un formulismo retórico, técnico y legal la mayoría de las veces similar: "Sepades que nos fue fecha relación..."; "Sepades que por parte de conçejo e regidores e ea çibdad nos fue fech a relación por una petiçion que en e nuestro consejo fue preentada..."; "...el dicho Alfonso Sánchez dixo que pedia e pedió al dicho juez que lo mandase ponr el dicho escripto en todos los procesos por él fechos"

26 "La vecindad derivaba del nacimiento en la población o de la habitación en ella por cierto tiempo (encendiendo fuego en la villa o ciudad, es decir, creando un hogar) acompañadas estas condiciones de la circunstancia de ser propietario en el lugar de bienes inmuebles (tener rayz) y de la admisión como vecino por el Concejo, y suponía para el vecino la protección del fuero local, el disfrute de los bienes comunales y la participación en el gobierno municipal”. García de Valdeavellano. (1968, p.543).

27 "El análisis del espacio público debería empezar con el reconocimiento de que su localización es estrictamente en el imaginario político. El espacio público es una ficción que, puesto que puede aparecer como verdadera, ejerce fuerza política real” (Sevillano Calero, F., 2005, p.189). 